\title{
Deformation of Poly(o-methoxyaniline) Film Induced by Polymer Conformation on Electrochemical Oxidation
}

\author{
Masamitsu KaneKo and Keiichi KANETO \\ Department of Computer Science and Electronics, Kyushu Institute of Technology, \\ 680-4 Kawazu, Iizuka, Fukuoka 820-8502, Japan
}

(Received April 3, 2000; Accepted September 22, 2000)

\begin{abstract}
KEY WORDS Artificial muscles / Electrochemomechanical Deformation / Conducting Polymers / Polyaniline / pH Dependence /
\end{abstract}

Biomimetic actuators that generate flexible and soft movement such as bending, expansion and twisting are of interest, since such motion is demanded for medical equipment, robotics and replacement for human muscles in the future. Various flexible and soft actuators have been fabricated using conducting polymers, ${ }^{1-3}$ gels, ${ }^{4}$ ion exchange membrane ${ }^{5}$ and nanotubes. ${ }^{6}$ These actuators are operated in electrolyte solution. In conducting polymers, driving force is generated by electrochemomechanical deformation (ECMD). The ECMD in conducting polymers such as polyaniline, ${ }^{3,7,8}$ polypyrrole, ${ }^{2,9,10}$ and polythiophene ${ }^{11}$ has been studied by fabricating actuators of laminate structures. These studies only provide qualitative behavior of actuation. It is required to measure directly the expansion and contraction of films for investigation of detailed mechanisms of ECMD. In our previous paper, ${ }^{12,13}$ on basic behavior in polyaniline films, it was clarified that typical expansion and the contraction force are $3 \%$ along films and $2-3 \mathrm{MPa}$, respectively.

Mechanisms of ECMD have been proposed, ${ }^{14}$ as (1) insertion and dedoping of bulky ions, (2) conformational change due to delocalization of $\pi$-electron, and (3) electrostatic repulsion between polycations. However, there has been no definitive study to clarify the mechanisms. The mechanism (1) has been conjectured as the primary mechanism. ${ }^{1,2,7}$ From ECMD behavior the magnitude of ECMD did not depend on the kind of anion in $\operatorname{poly}(o-$ methoxyaniline $)^{15}$ (PmAn) film at certain $\mathrm{pH}$. This is not explained satisfactorily by the mechanism (1). Mechanisms (2) and (3) should be used to fabricate artificial muscles exhibiting the larger and quicker response. Therefore, it is important to clarify the intrinsic mechanism of ECMD in conducting polymers for improvement of ECMD.

The $\mathrm{pH}$ dependence of ECMD along the longitudinal direction of PmAn film and expansion of the thickness direction in polyaniline film using variety of electrolyte solutions were studied. The role of conformation change of polymer structure to the ECMD is discussed.

\section{EXPERIMENTAL}

PmAn was synthesized by chemical polymerization of $o$-methoxyaniline. ${ }^{15}$ An aqueous solution of $0.1 \mathrm{M} o$ methoxyaniline and $1 \mathrm{M} p$-toluene sulfuric acid (TSA) was mixed with a solution of $0.4 \mathrm{M}$ ammonium peroxydi- sulfate and $1 \mathrm{M}$ TSA for $8 \mathrm{~h}$ at about $-5^{\circ} \mathrm{C}$. The obtained paste was washed with acetone for several times and then deprotonated by $0.1 \mathrm{M} \mathrm{NH}_{4} \mathrm{OH}$. The product of emeraldine base was dried in vacuo and dissolved in $\mathrm{N}$ methyl-2-pyrrolidinone (NMP) at 5\% wt. Emeraldine base films were prepared by casting the mixture on glass plate. The cast film was stretched mechanically more than 3 times of its original length. The sample film was a strip with dimensions of $15 \times 1.5 \mathrm{~mm}^{2}$ and the thickness of $50 \mu \mathrm{m}$ typically. The longitudinal direction of the strip was stretched direction and active length in the electrolyte solution was $9-12 \mathrm{~mm}$.

The ECMDs of the films were measured by special cells with a pinhole at the bottom and planer configuration as reported in our previous papers. ${ }^{12,13,16}$ Aqueous acid like TSA, $\mathrm{H}_{2} \mathrm{SO}_{4}, \mathrm{HBF}_{4}$, or $\mathrm{HCl}$ was used as electrolyte solution, and $\mathrm{pH}$ was tuned by changing the concentration of acids. The change of film dimension was measured using a laser displacement meter with an accuracy of $20 \mathrm{~nm}$. The cell was operated by a potentio/galvanostat, and redox current and response of laser displacement meter were measured and processed by personal computer. Ag wire was used as the reference electrode. The degree of oxidation was estimated from the cyclic voltammogram (CV), the current-voltage curve obtained by cycling the linear voltage sweep. The rate of expansion was defined as $\Delta l / l_{0}$, where $l_{0}$ and $\Delta l$ are original length and change of film length, respectively.

\section{RESULTS AND DISCUSSION}

The curves in Figure 1 show CV curves and $\Delta l$ in the longitudinal direction of PmAn for various $\mathrm{pH}$ of aqueous solution. Redox potential, $E_{\mathrm{a}}$ and $E_{\mathrm{c}}$, shifted to higher potentials and $\Delta l$ shrinks with decreasing $\mathrm{pH}$, where $E_{\mathrm{a}}$ and $E_{\mathrm{c}}$ are the potentials at anodic and cathodic current peaks, respectively, as shown in Figures 1 and 2 shows pH dependency of the half redox potential, $E_{1 / 2}=1 / 2\left(E_{\mathrm{a}}+E_{\mathrm{c}}\right)$, and $\Delta l / l_{0}$. The slope of $E_{1 / 2}$ against $\mathrm{pH}$ is $-69 \mathrm{mV} / \mathrm{pH}$ and the $\Delta l / l_{0}$ decreases markedly at $\mathrm{pH}$ lower than 2 .

Shifting of $E_{1 / 2}$ indicates that the redox reaction involves proton exchange between the film and electrolyte solution. The relationship between $E_{1 / 2}$ and $\mathrm{pH}$ is theoretically shown ${ }^{17}$ by an eq 1 for the reaction, $\mathrm{AH}_{m} \leftrightarrow \mathrm{A}$ $+m \mathrm{H}^{+}+n \mathrm{e}^{-}$, 




Figure 1. CV (upper curves) and change in film length (lower curves) as a function of bias potential vs. $\mathrm{Ag} / \mathrm{Ag}^{+}$in PmAn at various pHs.

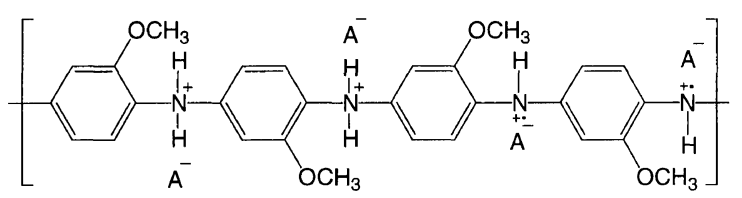

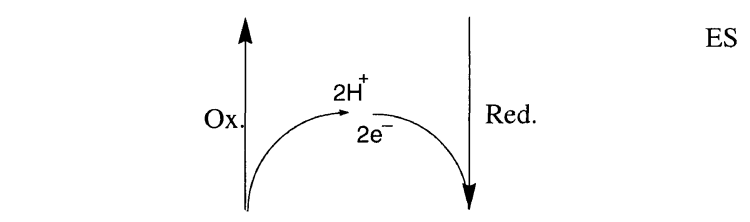

ES<smiles>[3H][NH+](c1ccc([NH+]([3H])c2ccc(N[CH])c(OC)c2)c(OC)c1)c1ccc([NH+]([3H])c2ccc(C)cc2OC)c(OC)c1</smiles>

LS

(a) $\mathrm{pH}<0$

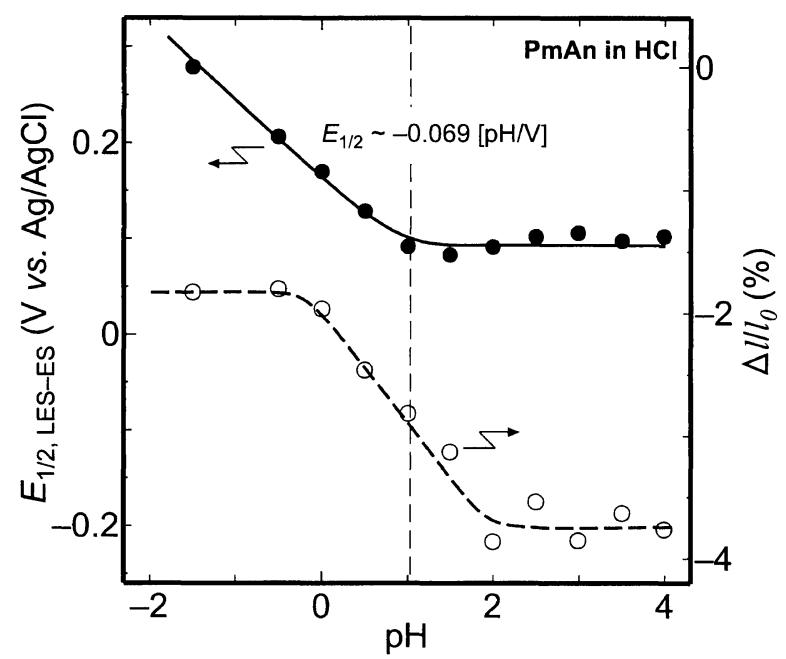

Figure 2. $\mathrm{pH}$ dependency of $E_{1 / 2}$ and $\Delta l / l_{0}$ in PmAn film.
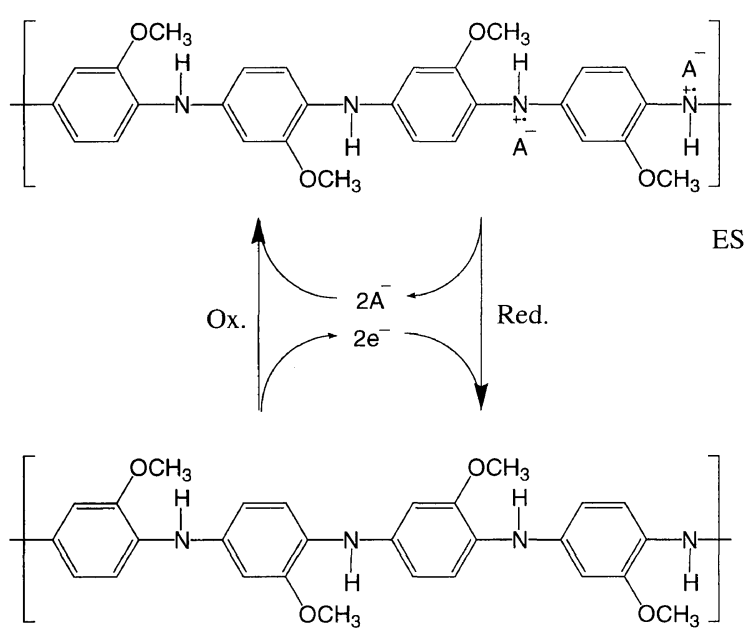

LS

(b) $\mathrm{pH}>2$

Figure 3. Schematic drawing of electrochemical reaction of poly (o-methoxyaniline) at (a) $\mathrm{pH}<0$ and (b) $\mathrm{pH}>2$.

$$
E_{\frac{1}{2}}=E^{0}{ }_{\frac{1}{2}}+\frac{0.059}{n} \log \frac{[\mathrm{A}]}{\left[\mathrm{AH}_{m}\right]}+0.059 \frac{m}{n} \log \left[\mathrm{H}^{+}\right]
$$

where $m$ and $n$ are the numbers of electron and proton, [A] and $\left[\mathrm{AH}_{m}\right]$ are active mass of the emeraldine and leucoemeraldine states, respectively. The slope of $-69 \mathrm{mV} /$ $\mathrm{pH}$ approximately agrees with $-59 \mathrm{mV} / \mathrm{pH}$ suggested by eq 1 for $n / m=1$ at room temperature. This indicates that a proton is expelled from the film by withdrawal of electron upon oxidation.

Electrochemical reaction of polyaniline typically occurs in three stages ${ }^{3,17}$ : leucoemeraldine salt (LS), emeraldine salt (ES) and pernigraniline salt. The pernigraniline salt that appears at higher potential is not stable, because of hydrolysis reaction. ES is electrically conductive and supposed to take an extended configuration of polymer due to delocalized $\pi$-electron charge carriers. LS is not in a conductive state. Electrochemical reac- tions ${ }^{17}$ depending on the $\mathrm{pH}$ between LS and ES are shown in Figure 3. At lower $\mathrm{pH}$, where proton concentration is high enough that nitrogen atoms form the tetrahedral ligand configuration, and protons are expelled upon oxidation as shown in Figure 3a. At higher $\mathrm{pH}$, oxidation takes place by anion doping into film shown in Figure $3 b$. Taking Figure $3 a$ into consideration, expansion of the film by the oxidation at $\mathrm{pH}<0$ results from the mechanisms of (2) and (3), and absolutely not from (1), because protons are expelled. The large expansion ratio at $\mathrm{pH}>0$ results from superimposed effects of all the mechanisms, and differences of $\Delta l / l_{0}$ at $\mathrm{pH}<0$ and $\mathrm{pH}>2$ may be attributed to the sum volume of protons and anions.

Expansions of PmAn film as a function of oxidation level, $y$, are shown in Figure $4 \mathrm{a}$ and $4 \mathrm{~b}$ for $\mathrm{pH} 0$ and $\mathrm{pH}$ 2.7 , respectively, in various electrolytes. The definition of $y(-0.5 \leq y \leq 0.5)$ is shown by the inset of Figure 4 as 

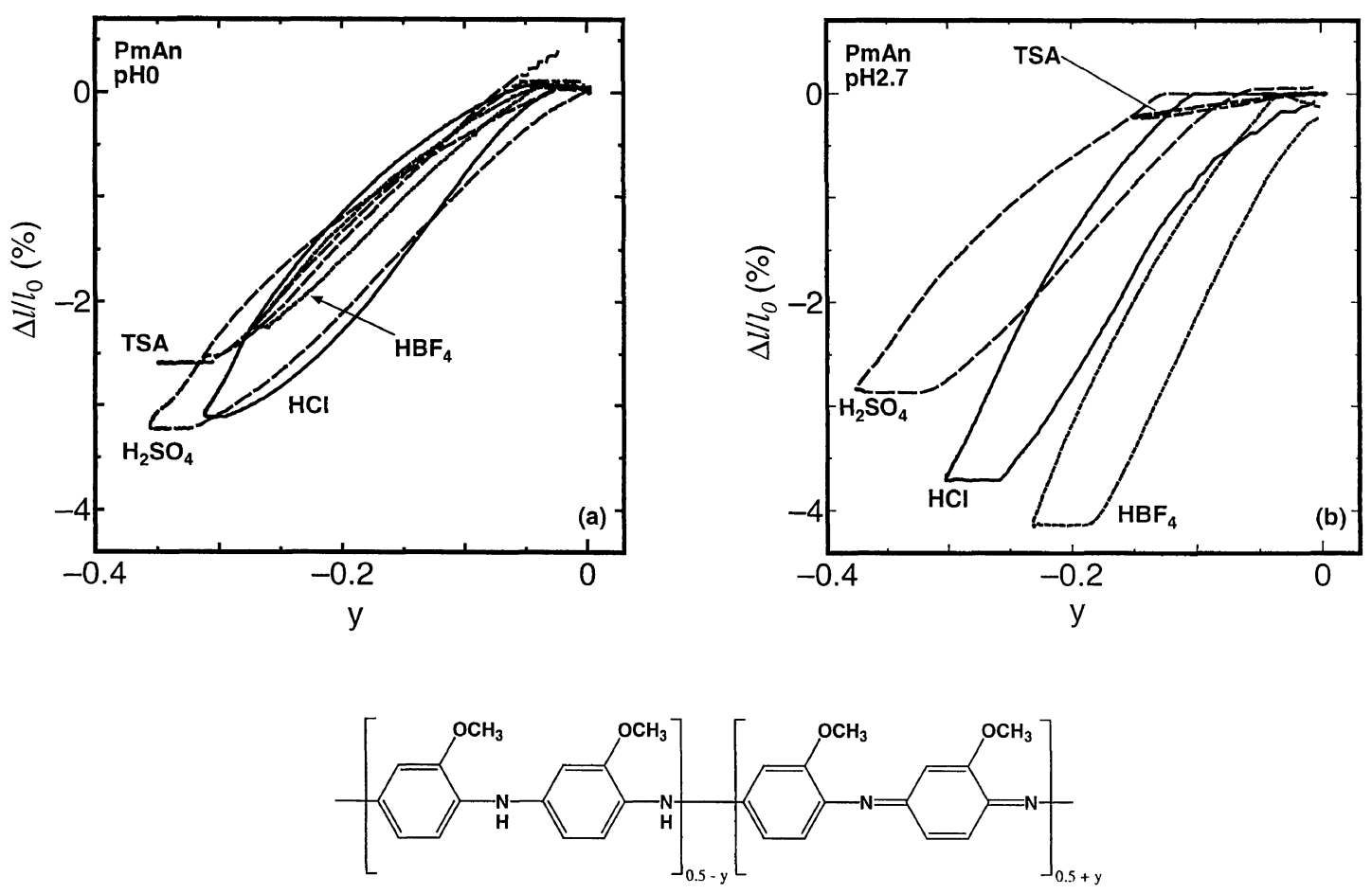

Figure 4. $\Delta l / l_{0}$ against oxidation level, $y$, in PmAn for $\mathrm{pH} 0$ and $\mathrm{pH} 2.7$. Definition of $y$ is shown by the inset, and ES state is taken as $y=0$.



Figure 5. Dependency of $\Delta l / l_{0}$ on ionic volume of electrolyte anions at $\mathrm{pH} 0$ and $\mathrm{pH} 2.7$ in PmAn film.

the base form for convenience. $y=0$ is the basis of the ES state and $y=-0.5$ is the complete LS state. Experimentally, $y$ was determined as rejected charge divided by reasonable charge injection. Plots of $\Delta l / l_{0} v s$. ionic volume $^{18,19}$ of the electrolytes for $\mathrm{pH} 0$ and $\mathrm{pH} 2.7$ are shown in Figure 5, where the volume of $\mathrm{SO}_{4}{ }^{2-}$ was calculated based on charge number. At pH 2.7 expansion markedly depends on the electrolyte, but not at $\mathrm{pH} 0$. Similar magnitude of $\Delta l / l_{0}$ to other anions was observed at $\mathrm{pH} 0$ as shown in Figure $4 \mathrm{a}$ for the electrolyte of TSA, whereas $\Delta l / l_{0}$ and reduction level for TSA were very small at $\mathrm{pH} 2.7$ (Figure $4 \mathrm{~b}$ ). This suggests that oxidation

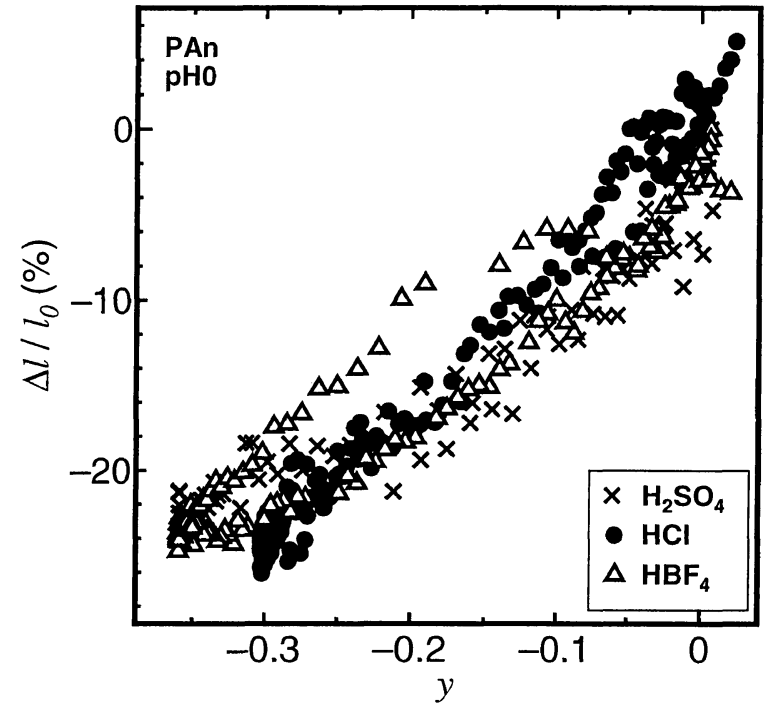

Figure 6. Expansion vs. $y$ of polyaniline film for the thickness direction in various electrolytes.

and reduction at $\mathrm{pH} 0$ take place mainly by insertion and exclusion of protons, and at $\mathrm{pH} 2.7$ they do primarily by anions. At $\mathrm{pH} 0$, slight anion dependence was observed.

Expansion, $\Delta l / l_{0}$, of the thickness direction in polyaniline cast film for various electrolytes at $\mathrm{pH} 0$ is shown in Figure 6. $\Delta l l_{0}$ is more than $20 \%$ and obviously does not depend on the electrolyte. This is in contrast to the previous finding that expansion of polyaniline film for the longitudinal direction at $\mathrm{pH} 0$ strongly depends on the electrolyte, ${ }^{12,19}$ as observed for PmAn at $\mathrm{pH} 2.7$. The large expansion for the thickness direction may be re- 




Figure 7. Schematic drawing of conformational change of cast film in the thickness direction.

lated to condensation process of the cast film. ${ }^{16}$ The evaporation of NMP solution from the cast film results in shrinking only in the thickness direction, but not in area. On oxidation, cast film thus has more freedom to expand in the thickness direction than longitudinal direction as shown in Figure 7. Expansion in the thickness direction of the cast film is due to change in polymer conformation and / or electrostatic repulsion.

\section{CONCLUSIONS}

To achieve large expansion and contraction of ECMD, change in polymer conformation as well as doping of bulky anions are useful. Change of polymer conformation is essential for ECMD. By fabricating the higherorder of polymer structure to optimize electrolytic expansion, the expansion and generated force more than natural muscles should improve.

\section{REFERENCES}

1. R. H. Baughman, Macromol. Chem. Macromol. Symp., 51, 193 (1991)

2. T. F. Otero, J. Rodriguez, E. Angulo, and C. Santamaria, Synth. Met., 55-57, 3713 (1993).

3. K. Kaneto, M. Kaneko, Y. Min, and A.G. MacDiarmid, Synth.
Met., 71, 2211 (1995).

4. Y. Osada, H. Okuzaki, and H. Hori, Nature (London), 6352, 242 (1992).

5. K. Oguro, Y. Kawami, and H. Takenaka, J. Micromachine Soc., 5, 27 (1992).

6. R. H. Baughman, C. Cui, A. A. Zakhidov, Z. Iqubal, J. N. Barisci, G. M. Spinks, G. G. Wallace, A. Mazzoldi, D. D. Rossi, A. G. Rinzler, O. Jaschinski, S. Roth, and M. Kertesz, Science, 284, 1340 (1999).

7. T. E. Herod and J. B. Schrenoff, Chem. Mater., 5, 951 (1993).

8. K. Kaneto, Y. Min, and A. G. MacDiarmid, U. S. Patent 5556 700 (Sept. 17, 1996).

9. Q. Pei and O. Inganäs, Synth. Met., 55-57, 3718 (1993).

10. E. Smela, O. Inganäs, and I. Lundström, Science, 268, 1735 (1995).

11. X. Chen and O. Inganäs, Synth. Met., 74, 159 (1995).

12. K. Kaneto, M. Kaneko, and W. Takashima, Jpn. J. Appl. Phys., Part 2, 34, L837 (1995).

13. W. Takashima, M. Fukui, M. Kaneko, and K. Kaneto, Jpn. J. Appl. Phys., Part 1, 34, 3786 (1995).

14. K. Kaneto, K. Kudo, Y. Ohmori, M. Onoda, and M. Iwamoto, IEICE Trans. ELECTRON., E81-C, 1009 (1998).

15. M. Kaneko and K. Kaneto, IEICE Trans. ELECTRON., E81C, 1064 (1998).

16. M. Kaneko and K. Kaneto, Synth. Met., 102, 1350 (1999).

17. W. H. Huang, B. D. Humphrey, and A. G. MacDiarmid, J. Chem. Soc., Faraday Trans. 1, 82, 2385 (1986).

18. M. Ue, Denki Kagaku, 62, 620 (1994).

19. M. Kaneko, M. Fukui, W. Takashima, and K. Kaneto, Synth. Met., 84, 795 (1997). 